Article

\title{
Cement Kiln By-Pass Dust: An Effective Alkaline Activator for Pozzolanic Materials
}

\author{
Lukáš Kalina *®i), Vlastimil Bílek Jr.Đ, Tomáš Kiripolský, Radoslav Novotný and Jiří Másilko \\ Materials Research Centre, Faculty of Chemistry, Brno University of Technology, Brno 61200, Czech Republic; \\ bilek@fch.vut.cz (V.B.J.); xckiripolsky@fch.vut.cz (T.K.); xcnovotny2@fch.vut.cz (R.N.); masilko@fch.vut.cz (J.M.) \\ * Correspondence: kalina@fch.vut.cz; Tel.: +42-054-114-9366
}

Received: 27 August 2018; Accepted: 18 September 2018; Published: 19 September 2018

\begin{abstract}
Cement kiln by-pass dust (CKD) is a fine-grained by-product of Portland clinker manufacturing. Its chemical composition is not suitable for returning back into feedstock and, therefore, it has to be discharged. Such an increasing waste production contributes to the high environmental impact of the cement industry. A possible solution for the ecological processing of CKD is its incorporation into alkali-activated blast furnace slag binders. Thanks to high alkaline content, CKD serves as an effective accelerator for latent hydraulic substances which positively affect their mechanical properties. It was found out that CKD in combination with sodium carbonate creates sodium hydroxide in situ which together with sodium water glass content increases the dissolution of blast furnace slag particles and subsequently binder phase formation resulting in better flexural and compressive strength development compared to the sample without it. At the same time, the addition of CKD compensates the autogenous shrinkage of alkali-activated materials reducing the risk of material cracking. On the other hand, this type of inorganic admixture accelerates the hydration process causing rapid loss of workability.
\end{abstract}

Keywords: cement kiln by-pass dust; alkali activation; blast furnace slag; admixture

\section{Introduction}

Worldwide, the material resource consumption increases and consequently large amounts of waste are released into the environment [1]. This phenomenon is also associated with Portland cement production. It is well known that cement production is responsible for approximately $7 \%$ of the world's $\mathrm{CO}_{2}$ emissions [2]. Moreover, the manufacturing of Portland clinker is associated with solid waste production. The cement kiln by-pass dust (CKD), is the typical by-product of the cement clinker burning process [3]. This material contains high concentrations of heavy metals and therefore should be disposed as a hazardous waste [4]. Nevertheless, the economic pressure caused by CKD disposal tends to its re-addition to the final cement product.

A possible way to ecologically process the CKD waste is utilization in alkali-activated materials formed via the reaction of a solid aluminosilicate with highly concentrated alkaline aqueous solution [5]. The alkali activation mechanism includes the destruction of the raw material by breaking the $\mathrm{Si}-\mathrm{O}-\mathrm{Si}$ and $\mathrm{Si}-\mathrm{O}-\mathrm{Al}$ bonds into lower stability structural units, their interaction through the coagulation-condensation process and the precipitation of final reaction products [6]. Thanks to the alkaline contents of CKD, especially due to the free lime, the significance of its usage as an alkaline activator arises. Previous studies $[7,8]$ show that the alkali activation process supported by reactive lime from CKD leads to the creation of calcium silicate binder phases. However, the $\mathrm{pH}$ value of alkaline solution with CKD is not high enough for sufficient decomposition of raw materials which in most cases need the addition of a typical alkaline activator such as sodium hydroxide [9,10]. In terms of working with such a caustic chemical compound, one must observe the safety regulations, which 
makes it more difficult in practical usage. Therefore, the study is focused on the alkali activation of blast furnace slag with CKD in connection with sodium carbonate resulting in sodium hydroxide according to Equations (1) and (2).

$$
\begin{gathered}
\mathrm{CaO}+\mathrm{H}_{2} \mathrm{O} \rightarrow \mathrm{Ca}(\mathrm{OH})_{2}, \\
\mathrm{Ca}(\mathrm{OH})_{2}+\mathrm{Na}_{2} \mathrm{CO}_{3} \rightarrow 2 \mathrm{NaOH}+\mathrm{CaCO}_{3},
\end{gathered}
$$

The caustic soda is formed gradually during the hydration process and increases the $\mathrm{pH}$ value in the pore solution which promotes the dissolution of aluminosilicate materials and thus positively affects the mechanical properties of the final products.

Thanks to the optimal chemical composition, the CKD seems to be an effective alkaline activator and plays a significant role in autogenous shrinkage mechanism in alkali-activated BFS materials. Therefore, CKD is a promising by-product material, and this paper is focused on its study and its possible utilization in these systems.

\section{Materials and Methods}

\subsection{Materials and Sample Preparation}

The main aluminosilicate material used to produce the alkali-activated mortars was blast furnace slag (BFS) with the Blaine fineness of $400 \mathrm{~m}^{2} \mathrm{~kg}^{-1}$ (ArcellorMittal Ostrava, a.s., Ostrava, Czech Republic). The cement kiln dust (CKD) was collected from the by-pass system of the Horné Srnie cement plant (Cemmac, a.s., Horné Srnie, Slovakia). The chemical composition of raw materials was determined by XRF as shown in Table 1. The XRD analysis of BFS indicated the presence of approximately $90 \%$ of amorphous phase determined with the method of internal standard (fluorite). The main minerals identified in BFS were melilite, calcite and merwinite. The CKD was composed of sylvite $(\mathrm{KCl})$, lime $(\mathrm{CaO})$, arcanite $\left(\mathrm{K}_{2} \mathrm{SO}_{4}\right)$, larnite $\left(2 \mathrm{CaO} \cdot \mathrm{SiO}_{2}\right)$, quartz $\left(\mathrm{SiO}_{2}\right)$, portlandite $\left(\mathrm{Ca}(\mathrm{OH})_{2}\right)$ and hatrutite $\left(3 \mathrm{CaO} \cdot \mathrm{SiO}_{2}\right)$. The free lime content determined according to EN 451-1 was $27.2 \mathrm{wt} \%$. The particle size distribution D50 of BFS and CKD determined by laser granulometry in dry state were $\sim 10 \mu \mathrm{m}$ and $\sim 4 \mu \mathrm{m}$, respectively. Anhydrous sodium carbonate (Penta, s.r.o., Prague, Czech Republic) in the form of powder and sodium water glass (Vodní sklo, a.s., Brno, Czech Republic) with the silica modulus of 2.2 were used as the alkaline activators. The $\mathrm{pH}$ value of used sodium water glass was 12.48. The $\mathrm{Na}_{2} \mathrm{O} / \mathrm{BFS}$ ratio was set to $8 \mathrm{wt} \%$.

Table 1. Chemical composition of BFS and CKD as determined by XRF.

\begin{tabular}{cccccccccccc}
\hline Raw Material & \multicolumn{10}{c}{ Chemical Composition/wt \% } \\
\hline & $\mathrm{SiO}_{2}$ & $\mathrm{Al}_{2} \mathrm{O}_{3}$ & $\mathrm{CaO}$ & $\mathrm{Na}_{2} \mathrm{O}$ & $\mathrm{K}_{2} \mathrm{O}$ & $\mathrm{MgO}$ & $\mathrm{SO}_{3}$ & $\mathrm{Fe}_{2} \mathrm{O}_{3}$ & $\mathrm{TiO}_{2}$ & $\mathrm{MnO}$ & $\mathrm{Cl}^{-}$ \\
\hline BFS & 34.7 & 9.1 & 41.1 & 0.4 & 0.9 & 10.5 & 1.4 & 0.3 & 1.0 & 0.6 & - \\
$\mathrm{CKD}$ & 11.9 & 4.2 & 45.7 & 0.4 & 16.9 & 0.9 & 7.2 & 2.4 & 0.3 & - & 10.1 \\
\hline
\end{tabular}

Alkali-activated BFS mortars with different amount of CKD at the expense of BFS $(0 ; 5 ; 10 ; 15$; $20 ; 25 \mathrm{wt} \%$ ) were prepared. The sand-to-BFS ratio was 3:1 using three different fractions of standard siliceous sand meeting requirements of EN 196-1 and the water-to-BFS ratio was set at 0.46 with respect to the water contained in the sodium water glass. The composition of mortars is shown in Table 2. Mixing and curing processes in molds were carried out at laboratory temperature $\left(25^{\circ} \mathrm{C}\right)$ with RH $99 \%$. After the demolding process ( 1 day), the specimens were stored in water at $25^{\circ} \mathrm{C}$ in the curing chamber. Prepared samples were subjected to compressive, flexural strength determination and length change measurements. 
Table 2. Composition of alkali-activated mortar samples (wt \%).

\begin{tabular}{ccccccc}
\hline Mixture Designation & REF & CKD-5 & CKD-10 & CKD-15 & CKD-20 & CKD-25 \\
\hline BFS & 21.6 & 20.5 & 19.4 & 18.3 & 17.2 & 16.1 \\
CKD & - & 1.1 & 2.2 & 3.3 & 4.4 & 5.5 \\
$\mathrm{Na}_{2} \mathrm{CO}_{3}$ & 2.1 & 2.1 & 2.1 & 2.1 & 2.1 & 2.1 \\
Na-water glass & 3.5 & 3.5 & 3.5 & 3.5 & 3.5 & 3.5 \\
water & 8.0 & 8.0 & 8.0 & 8.0 & 8.0 & 8.0 \\
standard sand & 64.8 & 64.8 & 64.8 & 64.8 & 64.8 & 64.8 \\
\hline
\end{tabular}

\subsection{Physical-Mechanical Measurements}

The samples with the dimensions of $4 \times 4 \times 16 \mathrm{~cm}$ were tested to determine their compressive and flexural strength according to EN 196-1. The strengths were tested at the age of 1, 7 and 28 days. The measurements were carried out by the compressive and bending strength tester Betonsystem Desttest 3310. The length changes for obtaining the shrinkage-expansion evolution were measured in short time intervals using the ASTM C490 apparatus for 28 days. The consistence of fresh alkali-activated mortars was measured based on the mini-cone test procedure in accordance with EN 1015-3. The effect of gradual CKD additions on the $\mathrm{pH}$ in water solution with dissolved sodium carbonate was measured using pH-meter S213 SevenCompact Duo (Mettler-Toledo GmbH, Greifensee, Switzerland) until the $\mathrm{pH}$ value was constant (approximately $10 \mathrm{~min}$ ).

\subsection{Isothermal Calorimetry}

The evolution of hydration heat was monitored using the TAM Air isothermal microcalorimeter (TA Instruments, New Castle, DE, USA). The measurements of heat evolution were performed at a constant temperature of $25^{\circ} \mathrm{C}$. When the thermal equilibrium was achieved, the BFS and alkaline activator were mixed together by injecting the solution into the $15 \mathrm{~mL}$ vial and stirring it for $3 \mathrm{~min}$. The water/BFS, as well as the $\mathrm{Na}_{2} \mathrm{O}$ /BFS mass ratio, were the same as in the preparation process of mortars. The heat evolution was recorded as the heat flow immediately.

\subsection{X-ray Diffraction Analysis (XRD)}

The X-ray powder diffraction of alkali-activated matrices after 7 days of curing was measured using the PANanalytical Empyrean diffractometer with $\mathrm{CuK} \alpha$ radiation equipped with a 3D detection system PIXcel3D. The specimens were step scanned from $5^{\circ}$ to $40^{\circ} 2 \theta$ using vertical high-resolution goniometer with the step size $0.013^{\circ} 2 \theta$. The samples with 0,10 and $20 \mathrm{wt} \%$ of CKD were used for the determination of mineralogical composition after the hydration process, moreover for the verification of reaction mechanism outlined in Equations (1) and (2).

\subsection{Thermogravimetry (TG)}

The behavior of the alkali-activated matrices during the thermal treatment was investigated using $70 \mathrm{mg}$ of the milled sample after 7 days of curing. The thermogravimetric analysis was performed using Q600 analyser (TA Instruments, New Castle, DE, USA) up to $1000{ }^{\circ} \mathrm{C}$ with the ramp $5{ }^{\circ} \mathrm{C}$ per minute and under the dried air conditions. The samples with 0,10 and $20 \mathrm{wt} \%$ of CKD addition were used for the quantification of the created calcium carbonate, formed according to Equation (2).

\section{Results and Discussion}

The compressive (Figure 1a) and flexural (Figure 1b) strengths development demonstrates a positive effect of CKD on mechanical properties. As observed in Figure 1a, the addition of CKD only slightly increases early compressive strengths after 1 and 7 days. However, a perspicuous improvement was achieved after 28 days, when all samples with the addition of CKD up to $20 \mathrm{wt} \%$ indicated higher strengths compared to the reference sample. Conversely, the substitution of $25 \mathrm{wt} \%$ BFS by CKD 
decreases the compressive strength which is related mainly to very quick loss of workability; this mixture is workable for only several minutes, as is shown in Figure 2. This strongly influences the homogeneity of samples.

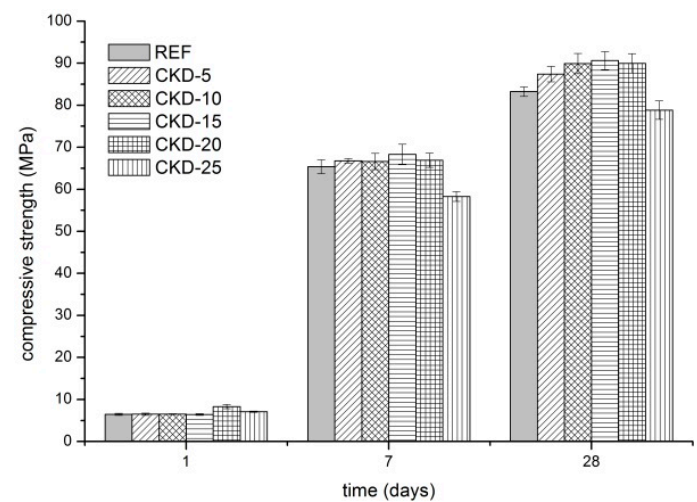

(a)

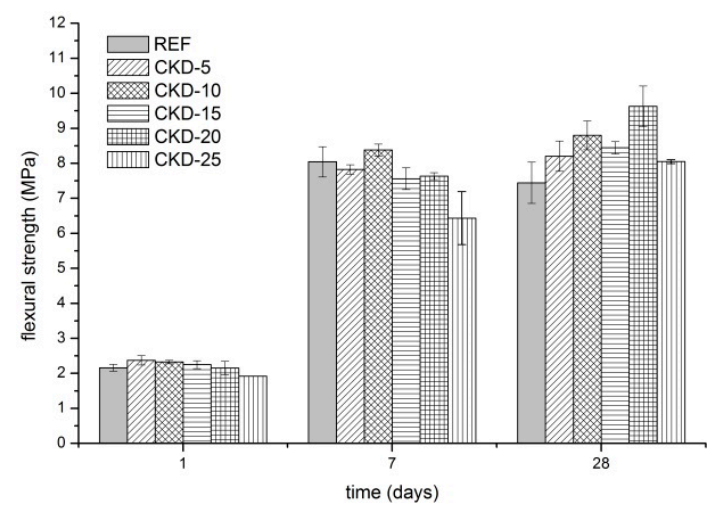

(b)

Figure 1. Compressive (a) and flexural (b) strengths development of alkali-activated mortars with different amounts of CKD.

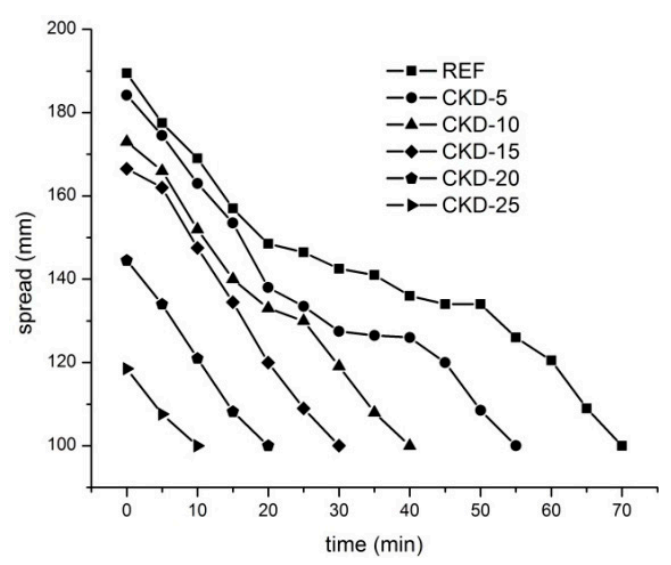

Figure 2. Workability over time of fresh alkali-activated mortars with different amount of CKD.

Considering the measurement incertitude expressed by the error bars in all measurements, the flexural strength development after 7 days suggests a convincing increase in strength compared to 1-day-old samples. However, a significant difference is noticeable after 28 days of curing. Whereas the samples with CKD content show an increase in flexural strengths, the reference sample has the opposite evolvement. This phenomenon likely relates to the chemical shrinkage of pure alkali-activated BFS which is described in several studies [11,12]. As a result, the internal stress is present in the material and, therefore, the microcracks in the structure can take place, which negatively influence the flexural strength especially.

The changes of samples length are shown in Figure 3. It is clearly visible that the reference sample exhibits the shrinkage which continues even after 1 day of mixing. This behavior in volume changes of alkali-activated BFS is in contrast with the binders based on ordinary Portland cements (OPC), since these binders cured continuously in water exhibit an increase in volume. This expansion, named as swelling, is connected with the absorption of water by the cement gel where the molecules of water act against cohesive forces and tend to force the gel particles away from each other [13]. On the other hand, the alkali-activated BFS forms CSH gel with the high atomic packing density which prevents water from penetrating into the inner structure during saturated (under water) curing [11] and causes self-desiccation. This process, which takes place in the interior of mortar mass, is known as autogenous volume change [13] and leads to the shrinkage of the whole system. A different situation occurs in the 
case of the samples with the CKD additions, the expansion of which depends on the amount of free lime contained therein. Free $\mathrm{CaO}$ is very well known as a cheap expansive agent, provided that it is burned at temperatures above $1000{ }^{\circ} \mathrm{C}$ resulting in "dead burnt lime" [14]. Such lime is also present in CKD, the collection of which from the Portland cement manufacturing process is carried out at the temperature of about $1100{ }^{\circ} \mathrm{C}$. From the evolution of expansion it is obvious that the complete expansion is achieved in less than 3 days in all samples. This certainly has its advantages in the lower affecting of the curing process as well as in the lower risk of presence of residual un-reacted $\mathrm{CaO}$ which could cause later expansion [15].

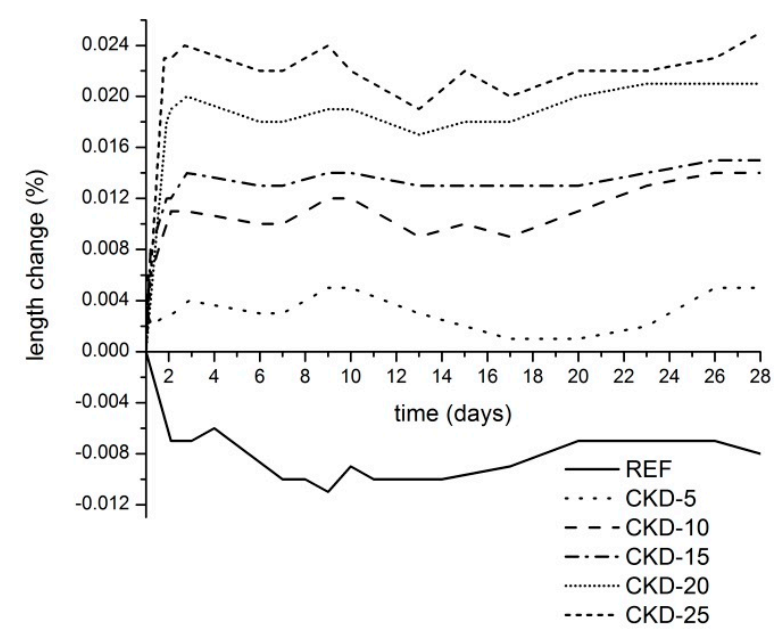

Figure 3. Length changes of alkali-activated mortars with different amounts of CKD during saturated (under water) curing.

The increase in mechanical properties of samples with CKD addition is also closely connected with higher dissolution of BFS and subsequent higher formation of binder phases. The dissolution of slag particles strongly depends on the $\mathrm{pH}$ of ambient solution [16]. It is obvious that CKD as well as sodium carbonate mixed separately with water indicate lower values of $\mathrm{pH}$ in comparison with their joint solution (Figure 4). Thanks to the reaction of lime contained in CKD and sodium carbonate in the water environment, described in Equations (1) and (2), the rise in $\mathrm{pH}$ up to the value over 13 occurs and the dissolution of slag particles rapidly increases.

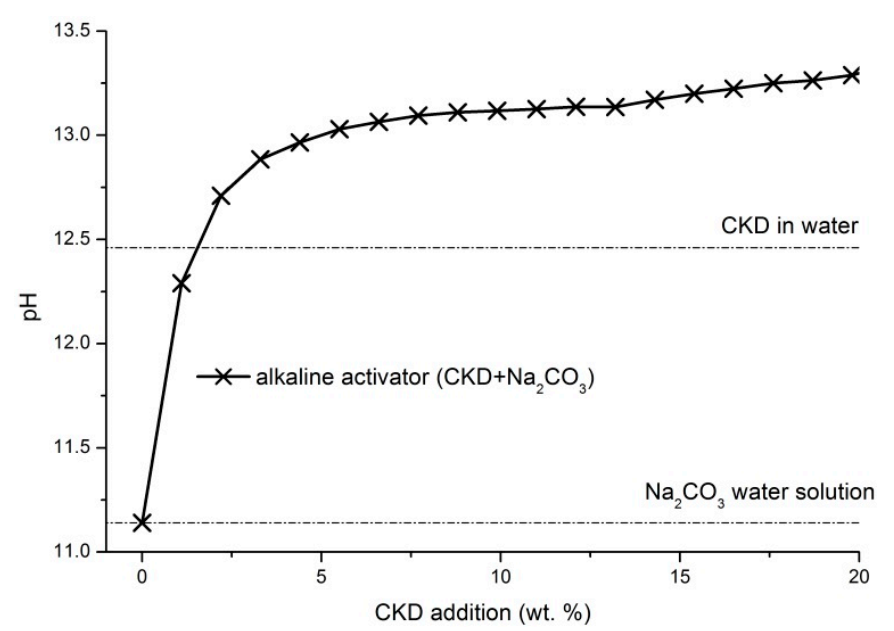

Figure 4. Effect of different amounts of $\mathrm{CKD}$ additions on the $\mathrm{pH}$ of water solution with dissolved sodium carbonate.

The process of dissolution of BFS and the creation of CSH gel was characterized through the isothermal calorimetry as shown in Figure 5. The first peak (Figure 5a), measured during the first 
minutes of hydration, is mainly associated with wetting and dissolution of BFS [17]. From the zoomed area it is clear that the samples with the higher content of CKD indicate higher heat flow which would confirm better dissolution of BFS particles. At the same time, the hydration of lime proceeds according Equation (1); therefore, the contribution of heat released by this reaction is also a part of the first peak. After that, the pre-induction band is observed belonging to the formation of primary CSH gel [18] and gaylussite $\left(\mathrm{Na}_{2} \mathrm{Ca}\left(\mathrm{CO}_{3}\right)_{2} \cdot 5 \mathrm{H}_{2} \mathrm{O}\right)$ which is one of the initial products in $\mathrm{Na}_{2} \mathrm{CO}_{3}$-activated slag binders [19]. The secondary formation of CSH gel is connected with the peaks from 10 to 40 hours. It is well observed that higher heat flow in this region was measured for the samples with a higher content of CKD. These results suggest that CKDs contribute to a larger formation of binder phase as proven by the measurement of the total amount of heat evolution (Figure $5 b$ ), which is particularly associated with the quantity of created $\mathrm{CSH}$ gel. The total heat was monitored within 4 days from the beginning of alkaline activation.

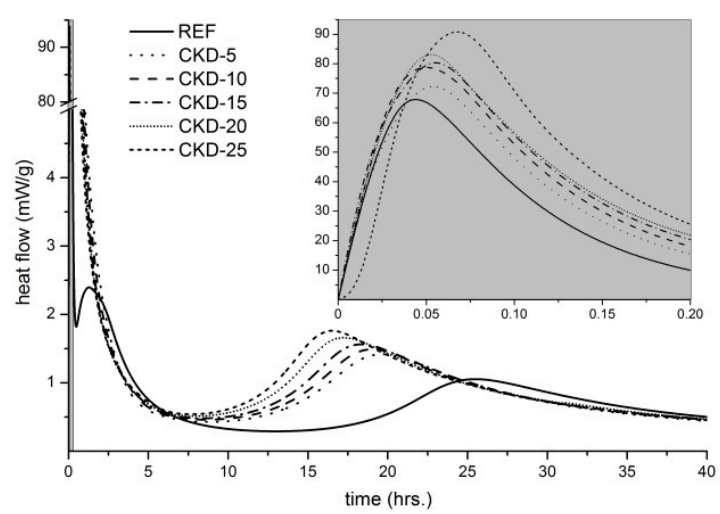

(a)

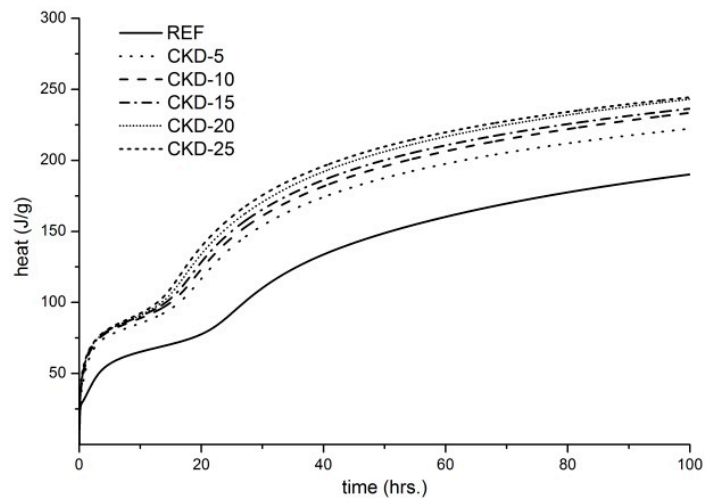

(b)

Figure 5. Evolution of heat flow (a) and total heat (b) of alkali-activated matrices with different amounts of CKD.

Subsequently, the samples were subjected to XRD analyses (Figure 6). The overlapped diffractograms show the presence of minerals from the raw materials plus gaylussite. The comparison of mineralogical composition among the samples with different amounts of CKD indicates no significant changes except in the formation of calcium carbonate. The samples with higher content of CKD create a considerably higher quantity of calcite, resulting primarily from Equation (2).

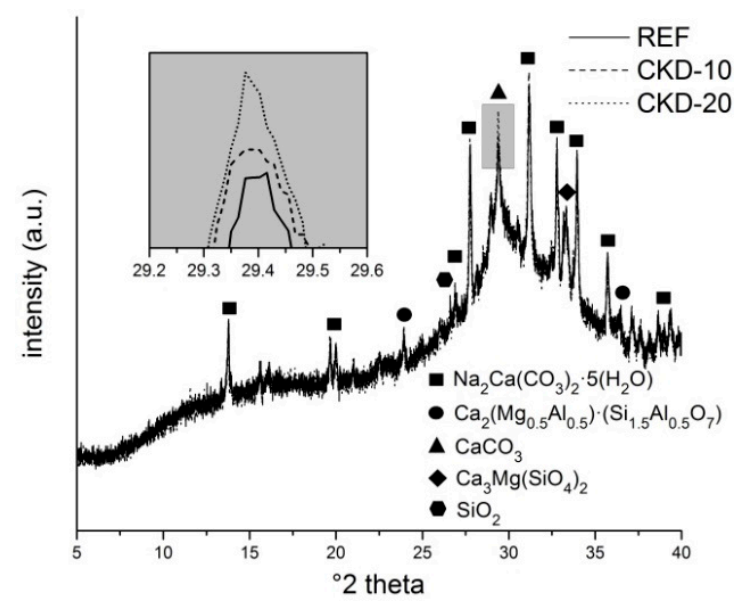

Figure 6. XRD of alkali-activated matrices with 0,10 and 20 wt \% of CKD addition.

The detailed quantitative information about the amount of formed calcium carbonate in prepared alkali-activated matrices was given by using of the thermogravimetric analysis. Figure 7 shows that 
the mass loss is connected with several ongoing processes during the heating. The first one between 31 and $240{ }^{\circ} \mathrm{C}$ can be associated with the loss of physically-bonded water and also the dehydration of chemically-bonded water from the newly formed CSH gel structure. The dehydration of interlayer water bonded in the $\mathrm{CSH}$ phase continues up to $600{ }^{\circ} \mathrm{C}$ [20]. The next process which appears around 600 to $800{ }^{\circ} \mathrm{C}$ can be attributed to the decomposition of carbonates. The first derivative of the TG analysis of the reference sample showed that the two step decomposition of carbonates takes place. The first step is supposed to be associated to the decomposition of gaylussite structure [21] and the second one to the calcite one [22]. The presence of both of them was confirmed by previous XRD analyses. However, it should be emphasized that the decomposition of the carbonate species should be intertwined together. The analyses of the samples with the CKD content shows the slightly different behaviour in this temperature range. It is obvious that the content of the gaylussite decreases with the expense of calcium carbonate, which was proven by the XRD analyses. From the conducted results we can conclude that the content of calcium carbonate increases with the reaction time. This phenomenon should be related with the carbonation process from some minor $\mathrm{CO}_{2}$ uptake onto the surface between the preparation of samples and TG analysis but it should also be a part of the reaction mechanism described in Equation (2).
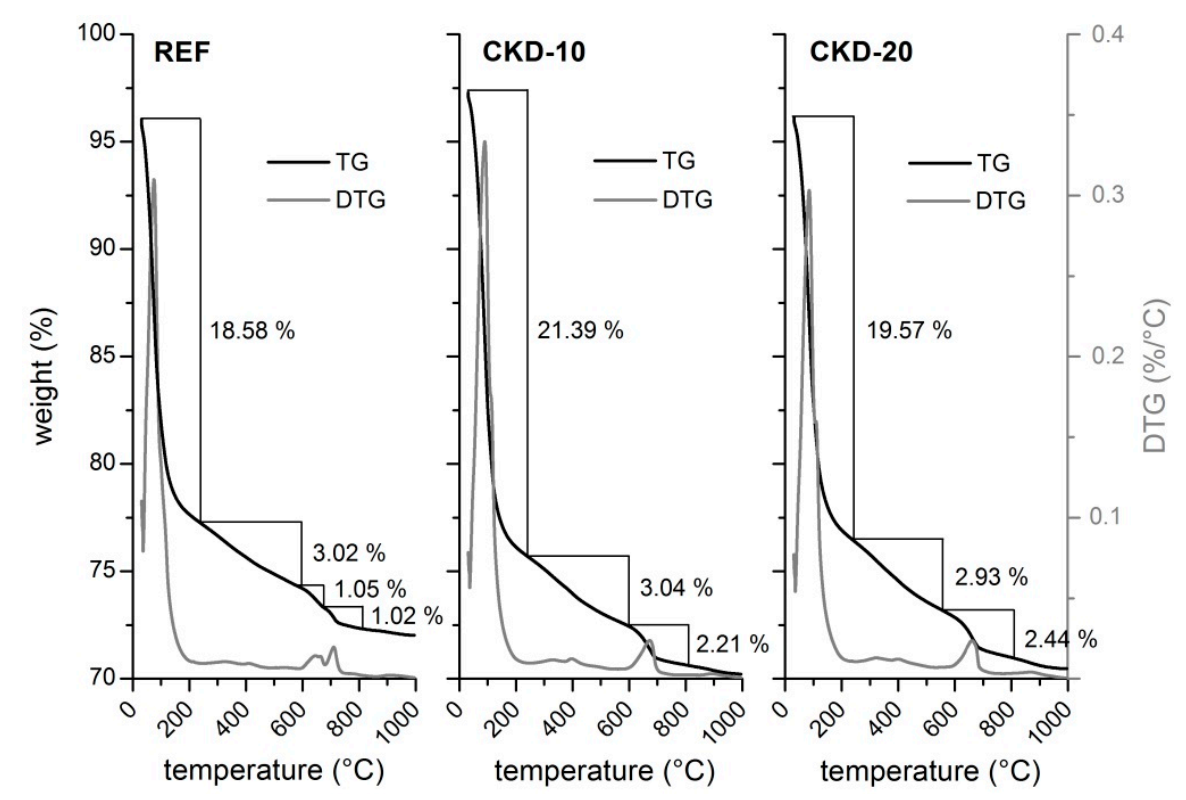

Figure 7. TG, DTG analyses of alkali-activated matrices with 0,10 and 20 wt \% of CKD addition.

\section{Conclusions}

The results of this study demonstrate that the secondary raw materials such as CKD can be successfully utilized for the alkaline activation of BFS. The following conclusions summarize the experimental part of the work:

1. The combination of $\mathrm{CKD}$ and sodium carbonate together with sodium water glass used as alkaline activators leads to the secondary formation of sodium hydroxide causing an increase in the $\mathrm{pH}$ of water solution in mixtures which promote the dissolution process of activated aluminosilicate.

2. Higher degree of BFS dissolution influences the hydration process in the sense of higher binder phase creation which positively affects the mechanical properties up to a certain limit.

3. The CKD content in alkali-activated BFS causes a small expansion of the whole system and thereafter the shrinkage cracking connected with the decrease of compressive as well as flexural strengths is reduced. 
4. The addition of CKD into the alkali-activated systems decreases the workability due to early hydration of lime resulting in the system inhomogeneity which can strongly influence the mechanical properties.

5. The production of alkali-activated BFS binders with CKD addition depends on its optimum dosage into the system, moreover, the CKD chemical and phase composition must always be taken into account.

Author Contributions: L.K. and V.B.J. conceived and designed the experiments; R.N. performed the microcalorimetry measurements; T.K. worked on the experimental parts; J.M. measured the XRD and TG-DTA analysis; L.K. wrote the paper.

Funding: This outcome has been achieved with the financial support by the project: Materials Research Centre at FCH BUT-Sustainability and Development, REG LO1211, with financial support from the National Programme for Sustainability I (Ministry of Education, Youth and Sports) and GA17-03670S “Development of shrinkage reducing agents designed for alkali activated systems", with financial support from the Czech Science Foundation and project of H2020 call-Marie Sklodowska-Curie-Research and Innovation Staff Exchange-GeoDust-734833 financed by European Union funds.

Conflicts of Interest: The authors declare no conflict of interest.

\section{References}

1. Blanchard, O. Energy-consumption and modes of industrialization-Four developing-countries. Energy Policy 1992, 20, 1174-1185. [CrossRef]

2. Mehta, P.K.; Monteiro, P.J.M. Concrete: Microstructure, Properties, and Materials; McGraw-Hill Education: New York, NY, USA, 2013.

3. Siddique, R. Utilization of cement kiln dust (CKD) in cement mortar and concrete-An overview. Resour. Conserv. Recycl. 2006, 48, 315-338. [CrossRef]

4. Eckert, J.O.; Guo, Q.H. Heavy metals in cement and cement kiln dust from kilns co-fired with hazardous waste-derived fuel: Application of EPA leaching and acid-digestion procedures. J. Hazard. Mater. 1998, 59, 55-93. [CrossRef]

5. Duxson, P.; Fernandez-Jimenez, A.; Provis, J.L.; Lukey, G.C.; Palomo, A.; van Deventer, J.S.J. Geopolymer technology: The current state of the art. J. Mater. Sci. 2007, 42, 2917-2933. [CrossRef]

6. Palomo, A.; Kavalerova, E.; Fernandez-Jimeneza, A.; Krivenko, P.; Garcia-Lodeiro, I.; Maltseva, O. A Review on Alkaline Activation: New Analytical Perspectives. 2015. Available online: http://digital.csic.es/handle/ 10261/110274 (accessed on 18 September 2018).

7. Konsta-Gdoutos, M.S.; Shah, S.P. Hydration and properties of novel blended cements based on cement kiln dust and blast furnace slag. Cem. Concr. Res. 2003, 33, 1269-1276. [CrossRef]

8. Lachemi, M.; Sahmaran, M.; Hossain, K.M.A.; Lotfy, A.; Shehata, M. Properties of controlled low-strength materials incorporating cement kiln dust and slag. Cem. Concr. Compos. 2010, 32, 623-629. [CrossRef]

9. Kalina, L.; Koplik, J.; Soukal, F.; Masilko, J.; Jaskowiecova, L. Potential uses of geopolymers to immobilize toxic metals from by-products materials. Environ. Eng. Manag. J. 2012, 11, 579-584. [CrossRef]

10. Wang, K.; Shah, S.P.; Mishulovich, A. Effects of curing temperature and $\mathrm{NaOH}$ addition on hydration and strength development of clinker-free CKD-fly ash binders. Cem. Concr. Res. 2004, 34, 299-309. [CrossRef]

11. Thomas, J.J.; Allen, A.J.; Jennings, H.M. Density and water content of nanoscale solid C-S-H formed in alkali-activated slag (AAS) paste and implications for chemical shrinkage. Cem. Concr. Res. 2012, 42, 377-383. [CrossRef]

12. Chen, W.; Brouwers, H.J.H. The hydration of slag, part 1: Reaction models for alkali-activated slag. J. Mater. Sci. 2007, 42, 428-443. [CrossRef]

13. Neville, A.M. Properties of Concrete, 5th ed.; Pearson: London, UK, 2011.

14. Troli, R.; Collepardi, M. Shrinkage-compensating concretes for special structures. In Proceedings of the 4 th International Conference on Non-Traditional Cement and Concrete, Brno, Czech Republic, 27-30 June 2011; pp. 18-36.

15. Collepardi, M.; Borsoi, A.; Collepardi, S.; Olagot, J.J.O.; Troli, R. Effects of shrinkage reducing admixture in shrinkage compensating concrete under non-wet curing conditions. Cem. Concr. Compos. 2005, 27, 704-708. [CrossRef] 
16. Li, C.; Sun, H.H.; Li, L.T. A review: The comparison between alkali-activated slag $(\mathrm{Si}+\mathrm{Ca})$ and metakaolin $(\mathrm{Si}+\mathrm{Al})$ cements. Cem. Concr. Res. 2010, 40, 1341-1349. [CrossRef]

17. Fernandez-Jimenez, A.; Puertas, F.; Arteaga, A. Determination of kinetic equations of alkaline activation of blast furnace slag by means of calorimetric data. J. Therm. Anal. Calorim. 1998, 52, 945-955. [CrossRef]

18. Shi, C.J.; Day, R.L. A calorimetric study of early hydration of alkali-slag cements. Cem. Concr. Res. 1995, 25, 1333-1346. [CrossRef]

19. Ke, X.Y.; Bernal, S.A.; Provis, J.L. Controlling the reaction kinetics of sodium carbonate-activated slag cements using calcined layered double hydroxides. Cem. Concr. Res. 2016, 81, 24-37. [CrossRef]

20. Bernal, S.A.; Rodriguez, E.D.; de Gutierrez, R.M.; Provis, J.L. Performance at High Temperature of Alkali-Activated Slag Pastes Produced with Silica Fume and Rice Husk Ash Based Activators. 2015. Available online: http:/ / materconstrucc.revistas.csic.es/index.php/materconstrucc/article/view/1689/2071 (accessed on 18 September 2018).

21. Johnson, D.R.; Robb, W.A. Gaylussite-Thermal properties by simultaneous thermal-analysis. Am. Mineral. J. Earth Planet. Mater. 1973, 58, 778-784.

22. Alarcon-Ruiz, L.; Platret, G.; Massieu, E.; Ehrlacher, A. The use of thermal analysis in assessing the effect of temperature on a cement paste. Cem. Concr. Res. 2005, 35, 609-613. [CrossRef]

(c) 2018 by the authors. Licensee MDPI, Basel, Switzerland. This article is an open access article distributed under the terms and conditions of the Creative Commons Attribution (CC BY) license (http://creativecommons.org/licenses/by/4.0/). 